\title{
Brucea javanica Leaf Extract Activates Caspase-9 and Caspase-3 of Mitochondrial Apoptotic Pathway in Human Oral Squamous Cell Carcinoma
}

\author{
Muhammad Ihsan Rizal ${ }^{1,2}$, Ferry Sandra ${ }^{1,2,3, *}$ \\ ${ }^{1}$ Department of Biochemistry and Molecular Biology, Division of Oral Biology, Faculty of Dentistry, Trisakti University, \\ J1. Kyai Tapa No.260, Jakarta, Indonesia \\ ${ }^{2}$ BioCORE Laboratory, Faculty of Dentistry, Trisakti University, Jl. Kyai Tapa No.260, Jakarta, Indonesia \\ ${ }^{3}$ Prodia Clinical Laboratory, Prodia Tower, Jl. Kramat Raya No.150, Jakarta, Indonesia \\ ${ }^{*}$ Corresponding author. E-mail: ferrysandra@gmail.com
}

Received date: Aug 29, 2015; Revised date: Sep 17, 2015; Accepted date: Sep 18, 2015

\section{Abstract}

$\mathrm{B}$

ACKGROUND: We previously reported Brucea javanica leaf extract (BJLE) induced apoptosis in human oral squamous cell carcinoma (HSC2) cells by attenuation of mitochondrial membrane permeability. However, further underlying mechanism is not known yet. Therefore, we conducted a study to investigate activation of Caspases related to attenuation of mitochondrial membrane permeability in BJLE-treated human oral squamous cell carcinoma.

METHODS: B. javanica leaves were collected, identified, minced, dried, extracted with distilled ethanol at room temperature for 24 hours, filtered and evaporated. Resulted BJLE was stored at $4^{\circ} \mathrm{C}$. HSC- 2 and HSC- 3 cells were fasted for 12 hours and treated with BJLE in various concentrations for 24 hours. Treated HSC-2 and HSC-3 cells were lysed and subjected to western blot, to detect cleaved-Caspase-9, cleaved-Caspase- 3 and $\beta$-actin. All visualized bands were captured and quantified.
RESULTS: Low numbers and morphological alterations of adherent HSC-2 and HSC-3 cells were observed in the group of cells treated with 500,100 and $10 \mu \mathrm{g} / \mathrm{mL}$ BJLE. Numbers of adherent HSC-2 and HSC-3 cells treated with BJLE were shown decreased along with the increase of BJLE concentrations. Meanwhile, numbers of floating HSC-2 and HSC-3 cells were increased. Bands of cleavedCaspase- 9 and cleaved-Caspase- 3 were observed in HSC2 and HSC-3 cells treated with 500 and $100 \mu \mathrm{g} / \mathrm{mL}$ BJLE. Higher-density bands of cleaved-Caspase- 9 and cleavedCaspase- 3 were observed in HSC-2 and HSC- 3 cells treated with $500 \mu \mathrm{g} / \mathrm{mL}$ BJLE than $100 \mu \mathrm{g} / \mathrm{mL}$ BJLE.

CONCLUSION: BJLE could induce apoptosis by activation of Caspase 9 and Caspase 3 of mitochondrial apoptotic pathway in human oral squamous cell carcinoma.

KEYWORDS: Brucea javanica, leaf, apoptosis, HSC-2, HSC-3, Caspase 9, Caspase 3

Indones Biomed J. 2016; 8(1): 43-8

\section{Introduction}

Many anticancer drugs are obtained from natural sources. Among them, reports in herbs have shown various potential for medicine.(1,2) The herbal medicine Brucea javanica (B. javanica) has demonstrated a variety of anti-cancer, anti-malarial, and anti-inflammatory properties. As an anti-cancer, B. javanica has been investigated in lung (3), gastrointestinal (3), cervical (4), non-small cell lung (5), hepatocellular (5), breast (5), oesophageal (5), pancreatic (6-8) and bladder (9) cancers. The anti-cancer property of B. javanica is specific, since there are significant differences in cytotoxicity between cervical cancer cells (CaSki, C33A, and HeLa) and normal keratinocyte (PHKs).(4) 
B. javanica extract induces cancer apoptosis. Apoptosis proceeds through a mitochondrial dependent pathway associated with Caspase 3 activation in MDAMB231 breast cancer cells.(5) Weak activation of Caspase 8 was observed upon B. javanica extract treatment in MDAMB231 cells.(5) On the other hand, Caspase 3 activity was highly activated in B. javanica extract-treated MDA-MB231 cells compared to untreated controls.(5) Study in T24 bladder cancer cells has shown that $B$. javanica significantly induced the expressions of Caspase- 3 and Caspase- 9 in T24 cells, whereas the expressions of nuclear factor (NF)- $\mathrm{kB}$ and cyclooxygenase (COX)-2 proteins were inhibited.(9) In addition the p53-dependent and p53-independent activities contribute to $B$. javanica extract-induced apoptosis.(4) Under treatment of $B$. javanica extract, $\mathrm{p} 53$ level of cervical cancer HeLa cells was increased and associated with apoptosis.(4)

We previously reported $B$. javanica leaf extract (BJLE) induced apoptosis in human oral squamous cell carcinoma (HSC2) cells by attenuation of mitochondrial membrane permeability.(10) However, further underlying mechanism is not known yet. Therefore, we conducted a study to investigate activation of Caspases related to attenuation of mitochondrial membrane permeability in BJLE-treated human oral squamous cell carcinoma.

\section{Methods}

\section{Plant Extraction}

BJLE was isolated as described by Wicaksono, et al.(10). Briefly, collected leaves were identified, minced, dried and extracted with distilled ethanol at room temperature for 24 hours. Further the solution as filtered and evaporated using rotatory evaporator. Resulted BJLE was stored at $4^{\circ} \mathrm{C}$.

\section{Cell Culture and BJLE Treatment}

Human oral squamous cell carcinoma (HSC)-2 and HSC-3 cells were cultured in Dulbecco's Modified Eagle's Medium (DMEM) with high glucose (Sigma Aldrich, St. Louis, MO, USA), supplemented with $10 \%$ fetal bovine serum (FBS) and $1 \%$ penicillin-streptomycin. HSC- 2 and HSC-3 cells were incubated in a humidified incubator with $5 \% \mathrm{CO}_{2}$, $37^{\circ} \mathrm{C}$. After HSC-2 and HSC-3 cells were seeded and fasted for 12 hours, BJLE was added in various concentrations. For a positive control, doxorubicin was added.

\section{Western blot}

Treated HSC-2 and HSC-3 cells were lysed with lysate buffer containing $50 \mathrm{mM}$ Hepes/NaOH, $0.5 \mathrm{M} \mathrm{NaCl}, 5 \mathrm{mM}$
EDTA, $20 \mathrm{mM} \beta$-mercaptoethanol, $0.2 \%$ Triton X-100, $50 \mathrm{mM}$ sodium fluoride, $30 \mathrm{mM}$ sodium pyrophosphate, $2 \mathrm{mM}$ sodium orthovanadate and $1 \mathrm{mM}$-amidinophenyl methanesulfonyl fluoride. Then $15 \mu \mathrm{g}$ lysates were separated by sodium dodecyl sulphate-polyacrylamide gel electrophoresis (SDS-PAGE) and transferred to a polyvinylidene difluoride sheet. After blocking with 5\% skimmed milk in phosphate buffered saline (PBS), the sheets were probed with the following 1:1000 diluted antibodies: rabbit polyclonal anti-cleaved-Caspase-9 (Asp315) (Cell Signaling, Beverly, MA, USA) and rabbit polyclonal anti-cleaved-Caspase-3 (Asp175) (Cell Signaling) antibodies. The secondary antibody was 1:2000 diluted horseradish peroxidase (HRP)-conjugated donkey anti-rabbit (Amersham, Buckinghamshire, UK) or antimouse (Amersham) IgG antibody. The bound antibodies were visualized using Immun Star HRP Chemiluminescent Kit (Bio-Rad Laboratories, Inc.). Membrane was then stripped with Seppro stripping buffer (Sigma-Aldrich), blocked with $5 \%$ skim milk in PBS, probed with mouse monoclonal anti- $\beta$-actin (C-4, Santa Cruz Biotechnology) antibodies), bound with anti-mouse IgG secondary antibody and visualized with chemiluminescent kit. All visualized bands were captured using Alliance 4.7 (UVItech, Ltd., Cambridge, UK) and quantified using UVIband software (UVItech, Ltd.).

\section{Results}

\section{Numbers and Morphological Alteration of BJLE-treated Cells}

High numbers and normal appearances of adherent HSC-2 (Figure 1A) and HSC-3 (Figure 2A) cells were shown in the untreated group. High numbers and unaffected appearances of adherent HSC-2 (Figure 1B) and -3 (Figure 2B) cells were also shown in the group of $1 \%$ DMSO-treated cells. In contrast, low numbers and morphological alterations of adherent HSC-2 cells were observed in the group of cells treated with $3 \mu \mathrm{M}$ Doxorubicin (Figure 1C), $500 \mu \mathrm{g} /$ $\mathrm{mL}$ BJLE (Figure 1D), $100 \mu \mathrm{g} / \mathrm{mL}$ BJLE (Figure 1E) and $10 \mu \mathrm{g} / \mathrm{mL}$ BJLE (Figure 1F). Similarly, low numbers and morphological alterations of adherent HSC-3 cells were also observed in the group of cells treated with $3 \mu \mathrm{M}$ Doxorubicin (Figure 2C), $500 \mu \mathrm{g} / \mathrm{mL}$ BJLE (Figure 2D), $100 \mu \mathrm{g} / \mathrm{mL}$ BJLE (Figure 2E) and $10 \mu \mathrm{g} / \mathrm{mL}$ BJLE (Figure $2 \mathrm{~F})$.

Numbers of adherent HSC-2 (Figure 1D-E) and HSC-3 (Figure 2D-E) cells treated with BJLE were shown decreased along with the increase of BJLE concentrations. 

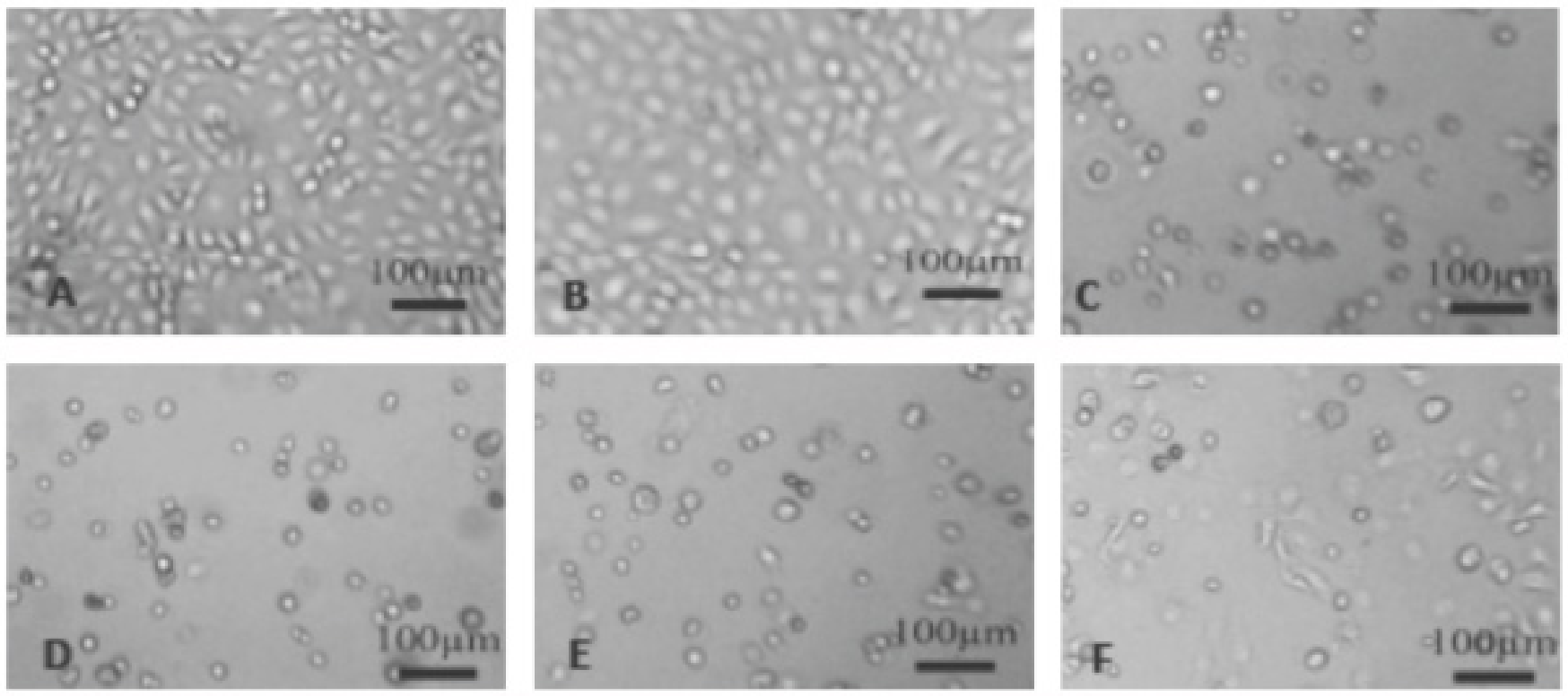

Figure 1. BJLE reduced number of HSC-2 cells. HSC-2 cells were untreated (A) or treated with 1\% DMSO (B), $3 \mu \mathrm{M}$ Doxorubicin (C), $500 \mu \mathrm{g} / \mathrm{mL}$ BJLE (D), $100 \mu \mathrm{g} / \mathrm{mL}$ BJLE (E) and $10 \mu \mathrm{g} / \mathrm{mL}$ BJLE (F) for 24 hours. Cells were documented under inverted microscope. Size bars were provided as indicated in the picture.

In addition, increasing numbers of floating HSC-2 (Figure 1D-E) and HSC-3 (Figure 2D-E) cells were observed along with the increase of BJLE concentrations as well.

\section{Activation of Caspase-9 and Caspase-3 in BJLE-treated Cells}

Bands of cleaved-Caspase- 9 and cleaved-Caspase- 3 were observed in HSC-2 (Figure 3A) and HSC-3 (Figure 3B) cells treated with doxorubicin, $500 \mu \mathrm{g} / \mathrm{mL}$ BJLE and 100 $\mu \mathrm{g} / \mathrm{mL}$ BJLE. Meanwhile, the bands were not observed in untreated, $1 \%$ DMSO or $10 \mu \mathrm{g} / \mathrm{mL}$ BJLE-treated HSC-2 and HSC-3 cells. Higher-density bands of cleaved-Caspase-9 and cleaved-Caspase- 3 were observed in HSC-2 and HSC-3 cells treated with $500 \mu \mathrm{g} / \mathrm{mL}$ BJLE than $100 \mu \mathrm{g} / \mathrm{mL}$ BJLE. Similar $\beta$-actin band densities were observed in all samples of HSC-2 and HSC- 3 cells.
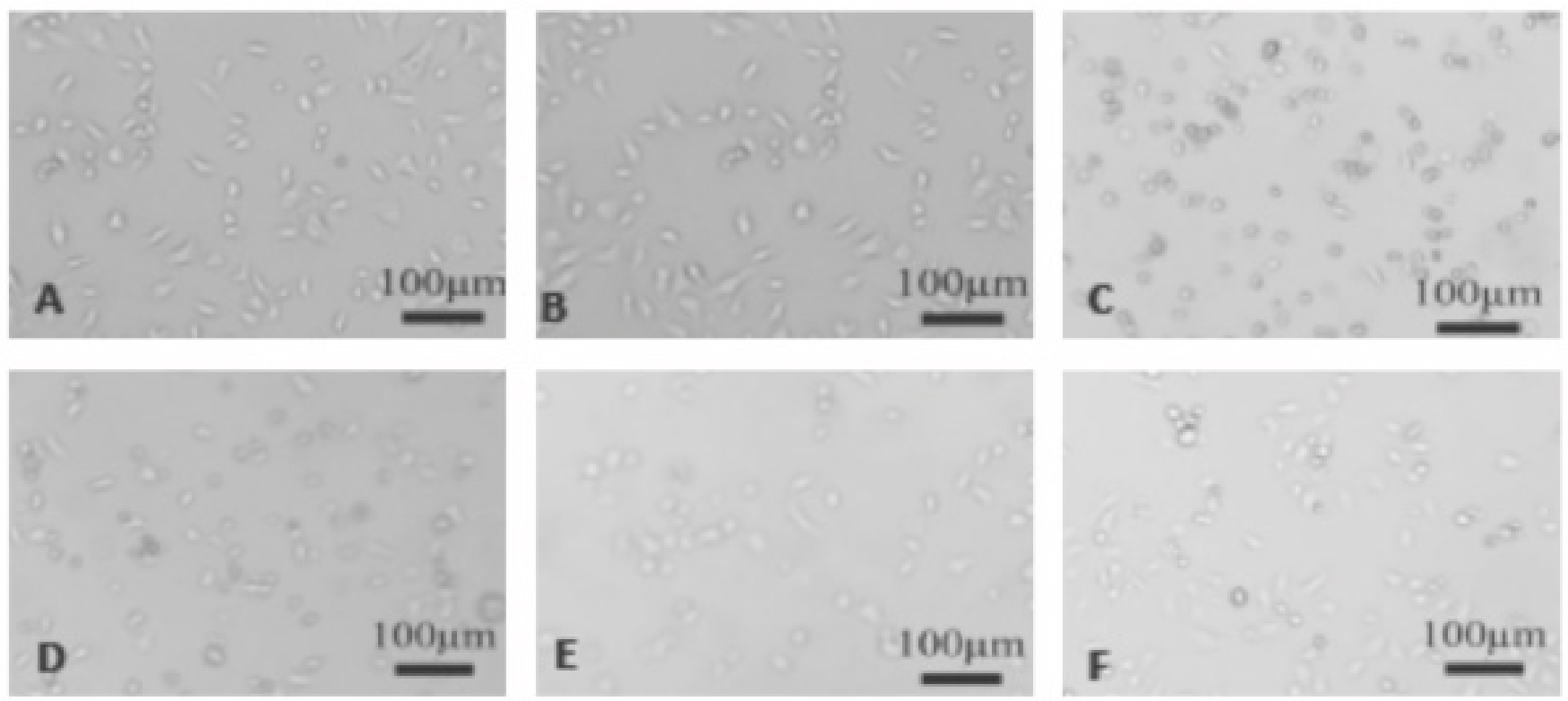

Figure 2. BJLE reduced number of HSC-3 cells. HSC-3 cells were untreated (A) or treated with 1\% DMSO (B), $3 \mu \mathrm{M}$ Doxorubicin (C), $500 \mu \mathrm{g} / \mathrm{mL}$ BJLE (D), $100 \mu \mathrm{g} / \mathrm{mL}$ BJLE (E) and $10 \mu \mathrm{g} / \mathrm{mL}$ BJLE (F) for 24 hours. Cells were documented under inverted microscope. Size bars were provided as indicated in the picture. 


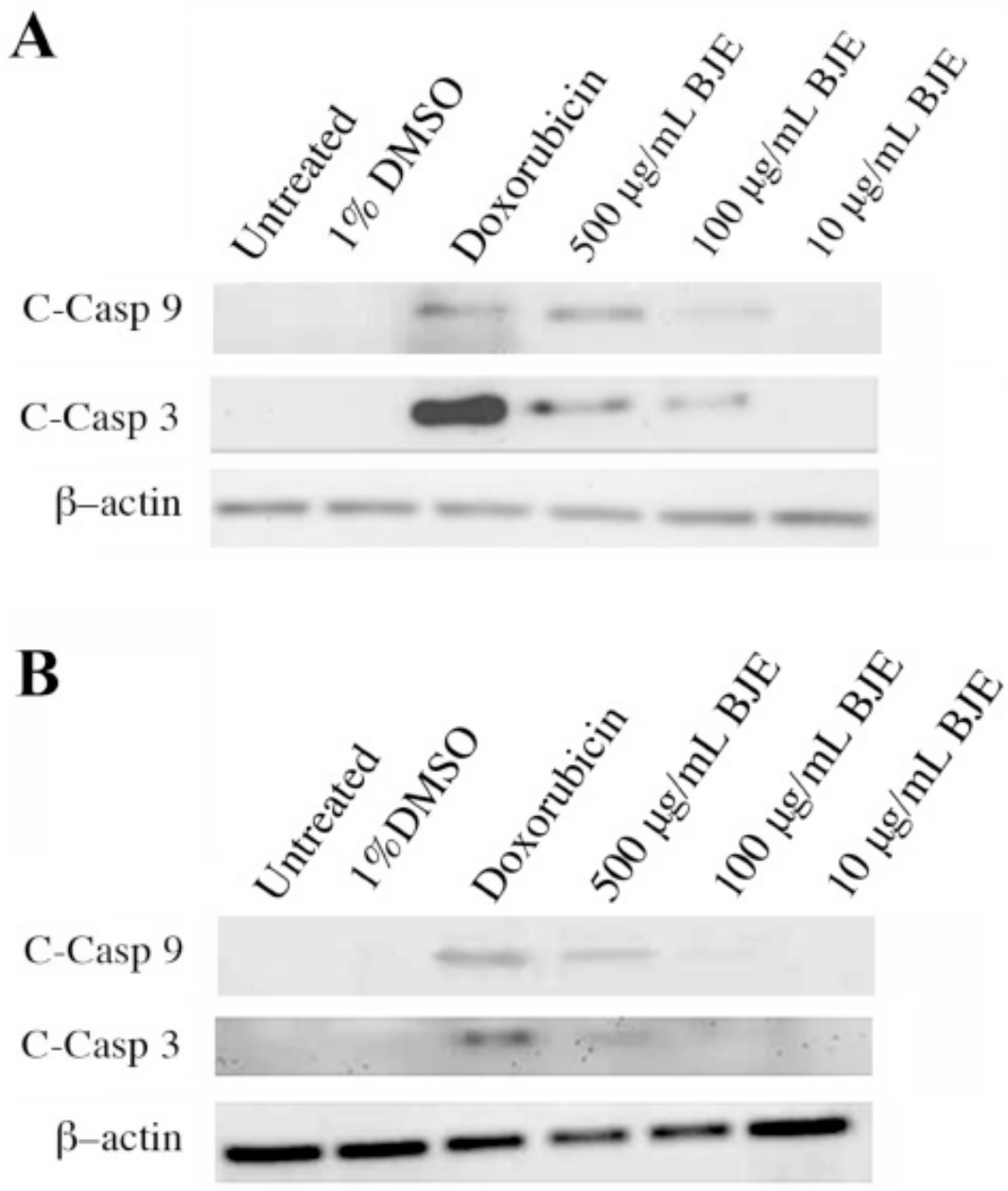

Figure 3. BJLE induced activation of Caspase-9 \& -3. HSC-2 (A) and -3 (B) cells were treated with 1\% DMSO, $3 \mu \mathrm{M}$ Doxorubicin, 500 $\mu \mathrm{g} / \mathrm{mL}$ BJLE, $100 \mu \mathrm{g} / \mathrm{mL}$ BJLE or $10 \mu \mathrm{g} / \mathrm{mL}$ BJLE as indicated in the panel, for 24 hours. Cells were collected, lysed, further processed for western blot analysis as described in Methods. C-Casp9: cleaved-Caspase 9; C-Casp3: cleaved-Caspase 3.

\section{Discussion}

Apoptosis has been suggested as a strategy for cancer chemotherapy.(11-14) Apoptotic morphological changes involve cytoplasmic shrinkage, plasma membrane blebbing, chromatin condensation and apoptotic bodies formation. (12) Double-strand cleavages of DNA occur in apoptotic cells.(11-16) Natural products have played a major role in apoptosis induction of osteosarcoma cells.(17,18) Due to the apoptosis induction by these natural products, several apoptosis-related proteins were induced, including Caspase 3, Caspase 7, Caspase 8 and Caspase 9, B cell lymphoma (Bcl)-2 and Survivin, Bcl-2-associated x protein (Bax), p53 upregulated modulator of apoptosis (Puma) and Fas.(18)

In our current study, we pursued a further investigation on BJLE-induced apoptosis mechanism related to attenuation of mitochondrial membrane permeability as we found earlier in our previous study. Current results show that treatment of BJLE decreased numbers of adherent HSC-2 and HSC- 3 cells, and increased floating HSC-2 and HSC-3 cells. This suggests that BJLE could decrease viable HSC-2 and HSC-3 cells by induction of apoptosis. This result is in accordance to our previous results(10) and other reports. (4-9) We also found that under treatment of BJLE, Caspase 9 and Caspase 3 were activated in HSC-2 and HSC- 3 cells, marked by high density of cleaved-Caspase 9 and cleavedCaspase 3. Among all BJLE concentrations tested, we found that cleaved-Caspase 9 and cleaved-Caspase 3 were clearly seen in HSC-2 and HSC-3 cells treated with $500 \mu \mathrm{g} / \mathrm{ml}$ BJLE and $100 \mu \mathrm{g} / \mathrm{ml} \mathrm{BJLE}$. These results are in accordance to lower numbers of adherent HSC-2 and HSC-3 cells, and 
higher numbers of floating HSC-2 and HSC-3 cells. When we look closely, densities of cleaved-Caspase 9 and cleavedCaspase 3 were higher in HSC-2 and HSC-3 cells treated with $500 \mu \mathrm{g} / \mathrm{ml} \mathrm{BJLE} \mathrm{compared} \mathrm{to} \mathrm{the} \mathrm{ones} \mathrm{treated} \mathrm{with} 100$ $\mu \mathrm{g} / \mathrm{ml}$ BJLE. Under treatment of $10 \mu \mathrm{g} / \mathrm{ml}$ BJLE, cleavedCaspase 9 and cleaved-Caspase 3 in HSC-2 and HSC- 3 cells were not detected. Along with that, numbers of adherent HSC-2 and HSC-3 cells were high, and numbers of floating HSC-2 and HSC-3 cells were low. This suggests that BJLE induced apoptosis of HSC-2 and HSC-3 in a concentration dependent manner.

Most of Caspases are apoptotic second messengers in signal transduction in cancer,(19) Inactivated Caspases are in the quiescent zymogen procaspase form and activation of pathway leads to cleavage (activation) and signal transduction.(20) In vitro, upstream Caspases can be activated by dimerization, while the executioner caspases require proteolytic cleavage. $(20,21)$ The upstream Caspases are activated through association with activation complexes, leading to conformational change and cleavage. (20) Downstream Caspases can only be activated by proteolytic cleavage of pro-domains by activated upstream Caspases $(20,22)$. Activated Caspases result in intracellular proteolysis of cytoskeletal components and proteins vital for organelle integrity towards cell execution (apoptosis). There are two main apoptotic signaling pathways, the extrinsic (death receptor-mediated) and intrinsic (mitochondrial) pathways. $(20,23)$

Since our current results showed that BJLE induced Caspase 9 and Caspase 3 in HSC-2 and HSC- 3 cells in a concentration dependent manner, which lead to apoptosis. Therefore,e suggest that BJLE could be an alternative potential agent for induction of apoptosis in HSC-2 and HSC-3 cells. However, we also realize that additional conformational study related to the specificity of Caspase 9 and Caspase 3-dependent pathway should be performed. It has been reported that combined with chemotherapy, B. javanica extract could improve quality of life in non small small cell lung cancer (NSCLC) patients without any increase in toxicity.(24) This shows a potential of BJLE as an alternative anti-osteosarcoma agent in the future.

\section{Conclusion}

Taken together, our results suggested that BJLE could induce apoptosis by activation of Caspase 9 and Caspase 3 of mitochondrial apoptotic pathway in human oral squamous cell carcinoma.

\section{References}

1. Arung ET, Wicaksono BD, Handoko YA, Kusuma IW, Shimizu K, Yulia D, et al. Cytotoxic effect of artocarpin on T47D cells. J Nat Med. 2010; 64: 423-9

2. Widowati W, Tjandrawati M, Risdian C, Ratnawati $\mathrm{H}$, Tjahjani $\mathrm{S}$, Sandra F. The comparison of antioxidative and proliferation inhibitor properties of Piper betle L., Catharanthus roseus [L] G. Don, Dendrophtoe petandra L., Curcuma mangga Val. extracts on T47D cancer cell line. Int Res J Biochem Bioinform. 2011; 1: 22-8.

3. Chen M, Chen R, Wang S, Tan W, Hu Y, Peng X, et al. Chemical components, pharmacological properties, and nanoparticulate delivery systems of Brucea javanica. Int J Nanomedicine. 2013; 8: 85-92.

4. Gao H, Lamusta J, Zhang WF, Salmonsen R, Liu Y, O'Connell E, et al. Tumor Cell Selective Cytotoxicity and Apoptosis Induction by an Herbal Preparation from Brucea javanica. N Am J Med Sci (Boston). 2011; 4: 62-6.

5. Lau FY, Chui CH, Gambari R, Kok SH, Kan KL, Cheng GY, et al Antiproliferative and apoptosis-inducing activity of Brucea javanica extract on human carcinoma cells. Int J Mol Med. 2005; 16: 115762.

4. Lau ST, Lin ZX, Zhao M, Leung PS. Brucea javanica fruit induces cytotoxicity and apoptosis in pancreatic adenocarcinoma cell lines. Phytother Res. 2008; 22: 477-86.

5. Lau ST, Lin ZX, Liao Y, Zhao M, Cheng CH, Leung PS. Bruceine $\mathrm{D}$ induces apoptosis in pancreatic adenocarcinoma cell line PANC1 through the activation of $\mathrm{p} 38$-mitogen activated protein kinase. Cancer Lett. 2009; 281: 42-52.

6. Liu L, Lin ZX, Leung PS, Chen LH, Zhao M, Liang J. Involvement of the mitochondrial pathway in bruceine D-induced apoptosis in Capan-2 human pancreatic adenocarcinoma cells. Int J Mol Med. 2012; 30: 93-9.

9. Lou GG, Yao HP, Xie LP. Brucea javanica oil induces apoptosis in T24 bladder cancer cells via upregulation of caspase-3, caspase-9, and inhibition of NF-kappaB and COX-2 expressions. Am J Chin Med. 2010; 38: 613-24.

10. Wicaksono BD, Tangkearung E, Sandra F. Brucea javanica Leaf Extract Induced Apoptosis in Human Oral Squamous Cell Carcinoma (HSC2) Cells by Attenuation of Mitochondrial Membrane Permeability. Indones Biomed J. 2015; 7: 107-10.

11. Sandra F, Hendarmin L, Nakao Y, Nakamura N, Nakamura S. TRAIL cleaves caspase- $8,-9$ and -3 of AM-1 cells: a possible pathway for TRAIL to induce apoptosis in ameloblastoma. Tumour Biol. 2005; 26: 258-64.

12. Cho WH, Lee HJ, Choi YJ, Oh JH, Kim HS, Cho HS. Capsaicin induces apoptosis in MG63 human osteosarcoma cells via the caspase cascade and the antioxidant enzyme system. Mol Med Rep. 2013; 8: 1655-62.

13. Wong RS. Apoptosis in cancer: from pathogenesis to treatment. J Exp Clin Cancer Res. 2011; 30: 87. doi: 10.1186/1756-9966-30-87.

14. Yang J, Zhang W. New molecular insights into osteosarcoma targeted therapy. Curr Opin Oncol. 2013; 25: 398-406.

15. Nagata S. DNA degradation in development and programmed cell death. Annu Rev Immunol. 2005; 23: 853-75.

16. Sandra F, Khosravi-Far R. Survivin S81 A Enhanced TRAIL's Activity in Inducing Apoptosis. Indones Biomed J. 2010; 2: 113-7.

17. Ji T, Lin C, Krill LS, Eskander R, Guo Y, Zi X, et al. Flavokawain $\mathrm{B}$, a kava chalcone, inhibits growth of human osteosarcoma cells through G2/M cell cycle arrest and apoptosis. Mol Cancer. 2013; 12: 55. doi: 10.1186/1476-4598-12-55. 
18. Wang H, Zhou JW, Fu DH, Zhou Y, Cheng WZ, Liu ZL. Gynura procumbens ethanolic extract suppresses osteosarcoma cell proliferation and metastasis in vitro. Oncol Lett. 2013; 6: 113-7.

19. Khan Z, Bisen PS. Oncoapoptotic signaling and deregulated target genes in cancers: special reference to oral cancer. Biochim Biophys Acta. 2013; 1836(1): 123-45.

20. Hensley P, Mishra M, Kyprianou N. Targeting caspases in cancer therapeutics. Biol Chem. 2013; 394(7): 831-43.

21. Fuentes-Prior P, Salvesen GS. The protein structures that shape caspase activity, specificity, activation and inhibition. Biochem J. 2004; 384: 201-32.
22. Favaloro B, Allocati N, Graziano V, Di Ilio C, De Laurenzi V. Role of apoptosis in disease. Aging (Albany NY). 2012; 4: 330-49.

23. Sandra F, Degli Esposti M, Ndebele K, Gona P, Knight D, Rosenquist $\mathrm{M}$, et al. Tumor necrosis factor-related apoptosis-inducing ligand alters mitochondrial membrane lipids. Cancer Res. 2005; 65(18): 8286-97.

24. Ji ZQ, Huang XE, Wu XY, Liu J, Wang L, Tang JH. Safety of Brucea javanica and cantharidin combined with chemotherapy for treatment of NSCLC patients. Asian Pac J Cancer Prev. 2014; 15: 8603-5. 